\title{
Effect of intradialytic exercise on fatigue, electrolytes level and blood pressure in hemodialysis patients: A randomized controlled trial
}

\author{
Hanan Mohamed Mohamed Soliman * \\ Faculty of Nursing, Mansoura University, El Mansoura, Egypt
}

Received: April 11, 2015

DOI: $10.5430 /$ jnep.v5n $11 \mathrm{p} 16$

\author{
Accepted: July 8, 2015 \\ Online Published: August 12, 2015 \\ URL: http://dx.doi.org/10.5430/jnep.v5n11p16
}

\begin{abstract}
Background: Hemodialysis is a physically stressful procedure and most of the patients will have fatigue and thereby an alteration in the electrolytes, hemoglobin level. Physical Exercises provided during Hemodialysis session do not cost patients extra time and will be effective in reducing fatigue level and enhancing potential for performing their activities of daily living $\&$ may increase the waste removal. Objective: This study was conducted to determine the impact of an eight-week Intradialytic Range of Motion Exercise program (consisting of 15 minutes low-intensity exercise during the first 2 hours of Hemodialysis) on Fatigue, electrolytes levels, Hemoglobin and Blood pressure.

Methods: A randomized controlled pre test post test design was utilized in this study in a hemodialysis unit, a total of 30 hemodialysis patients were enrolled into the study and randomly allocated into two groups. The experimental (The exercise group) $(\mathrm{n}=18)$ and the control group $(\mathrm{n}=12)$. Range of Motion Exercises were done in the experimental group for $15 \mathrm{~min} / \mathrm{day}$, three times a week for 2 months. Fatigue was measured via a Iowa Fatigue Scale (IFS) and Physiologic Parameters Form to measure serum electrolyte level, hemoglobin and blood pressure pre and post as well as at the end of each month after the intervention in both groups.

Results: After an 8-week of Intradialytic Range of Motion Exercises program, a significant reduction were seen in fatigue level, serum phosphate and potassium, calcium, urea, creatinine and a slight increase in hemoglobin level. Systolic and diastolic blood pressure changed significantly in the exercise group $(p<.05)$.

Conclusions: A simplified physical exercise program may be considered as a safe, and effective clinical nursing modality in patients with end-stage renal disease on Hemodialysis.
\end{abstract}

Key Words: Intradialytic exercise, Hemodialysis, Electrolytes levels, Fatigue, Blood pressure

\section{INTRODUCTION}

Chronic kidney disease (CKD) is a very important epidemic and public health problem that occurs in many countries with an increasing prevalence. ${ }^{[1]}$ Over 50 million individual throughout the world are known to have CKD and of those, over one million need renal replacement therapies such as dialysis and renal transplantation. In recent years, increasing the incidence of D.M and hypertension, the foremost common two reasons of CKD, have caused an increase in the prevalence of CKD. ${ }^{[2]}$ End-stage renal disease (ESRD) is an expensive and disabling condition with a high mortality rate. ESRD, in 2006, costs reached to $\$ 23$ billion, > 6\%

\footnotetext{
*Correspondence: Hanan Mohamed Mohamed Soliman; Email: hanansoliman697@ymail.com; Address: Faculty of Nursing, Mansoura University, El Mansoura, Egypt.
} 
of the health care budget, and mortality rates were approximately eight times greater among ESRD people aged 20-66 years treated by dialysis than those in the general population of comparable age group. ${ }^{[3]}$ The incidence of ESRD continues to increase each year. ${ }^{[4]}$ In the United States Approximately 100,000 new cases undergoing hemodialysis. ${ }^{\text {[5] }}$ The intervention is often prescribed three times each week, 3-6 hours per session, and remains through the patient's life or until successful kidney transplantation. ${ }^{[6]}$ Complications related to haemodialysis procedure are important and account for the costs of dialysis therapy. ${ }^{[7]}$ Basically, a vital point within the management of patients undergoing maintenance haemodialysis is that the assessment of the adequacy of dialysis. Merely following the Blood Urea Nitrogen (BUN) is insufficient as a result of a low BUN can reflect inadequate nutrition rather than sufficient dialytic urea removal. ${ }^{[8]}$ Inadequacy of dialysis responsible for disability and mortality for dialysis patients. So, to improve prognosis of dialysis patients its necessary to enhance adequacy of dialysis. ${ }^{\text {[9] }}$ Caring for patients with CKD and ESRD challenges all health care workers. Whereas patients in the hospital needs nurses to demonstrate knowledge of renal disease and renal pathology, and expertise in the identification and management of fatigue that usually impacts patients' quality of life. Interestingly several studies show that most of the patients on dialysis suffer from fatigue. ${ }^{[10,11]}$ In a study done by Murtaugh et al. about the prevalence of symptoms in ESRD they found that fatigue ranges from $60 \%$ to $97 \% .{ }^{[12]}$ It's important to caution assess and manage of fatigue to improve outcome of patients receiving dialysis. Fatigue usually not identified adequately and thus under-treated. ${ }^{[13]}$ Basically, fatigue represented as weakness, lack of energy and feeling of exhaustion. ${ }^{[7]}$ Fatigue affects not only day life but also disturbed daily selfcare activities, emotional status, and therefore the quality of life. ${ }^{[1,6,8]}$ There is a positive association between fatigue level and activity level, As a result of diminish activity, the individual's strength reduced, that increases fatigue and depression. ${ }^{[5,6]}$ Ninety four of hemodialysis patients tend to undergo further dialysis sessions if it would elevate their energy. ${ }^{[9,10]}$ All patients with CKD revealed fatigue as a most prominent clinical symptoms. ${ }^{[7,8,10,13,14]}$

Furthermore Jhamb et al. study revealed that ESRD patients experienced sever fatigue. ${ }^{[9]}$ All the same, due to subjective nature of fatigue. ${ }^{[1,15]}$ Fatigue management include pharmacologic and life style modifications. The former technique include (vitamin C, L-carnitine, and different medications as well as erythropoietin to overcome anemia). Second technique include (relaxation as yoga, exercise, acupuncture, electric stimulation, and dialysis). ${ }^{[14]}$ The above mentioned management used effectively to eliminate fatigue in

Published by Sciedu Press hemodialysis patients. Interestingly Exercise alleviate deterioration produced by aging process, diseases, and inactive lifestyle. ${ }^{[15]}$ In spite of research studies confirmed safety and the effectiveness Intradialytic exercise on eliminating fatigue however intra dialytic exercise not routinely offered adjacent therapy to dialysis. Additionally decreased number of patients and drop out of those participating in the exercise program. ${ }^{[16,17]}$ An exercise protocol could lead to improvements in many functions, such as blood pressure, heart function (especially ventricular function in hemodialysis [HD] patients), muscle strength, and respiratory capacity, and reduce muscle atrophy, with excellent results for the QOL. ${ }^{[17]}$

Therefore there is an urgent need to treat fatigue so as to decrease its impact on the life of patient undergoing hemodialysis. The nurse has a pivotal role and responsible for evaluating fatigue and institute measures that directly eliminate its impact. The aim of the present study was to determine the impact of an eight-week Intradialytic Range of Motion Exercise (ROM) on Fatigue, Serum electrolytes levels, Hemoglobin and Blood pressure.

\section{RESEARCH METHODS}

\subsection{Aim of the study}

The aim of this study was to determine the impact of Intradialytic ROM exercise on Fatigue, Serum electrolytes levels, Hemoglobin and Blood pressure among patients subjected to Hemodialysis.

\subsection{Research design}

The research design selected for the study was a randomized controlled trial, two group pretest post-test design.

\subsection{Hypotheses}

All hypotheses will be tested at $(p<.05)$ level of significance.

H1: Hemodialysis patients who involved in practicing Intradialytic Exercise will develop a significant reduction in fatigue level at the end of each month than those in control group.

H2: Hemodialysis patients who involved in practicing Intradialytic Exercise will develop a significant improvement in serum electrolytes level at the end of each month than those in control group.

H3: Hemodialysis patients who involved in practicing Intradialytic Exercise will develop a significant improvement in hemoglobin level at the end of each month than those in control group.

H4: Hemodialysis patients who involved in practicing Intradialytic Exercise will develop a significant improvement 
in systolic and diastolic blood pressure at the end of each month than those in control group.

H5: There is a significant association between level of fatigue and selected socio- demographic variables among experimental and control group.

\subsection{Variables of the study}

Dependent variables: Dependent variables in this study was fatigue level, blood pressure reading and Serum electrolytes level (Potassium, Calcium, Phosphate, Hemoglobin, Serum urea, Serum creatinine).

Independent variables: The independent variables in this study was Intradialytic ROM and Routine care.

\subsection{Setting of the study}

The study was carried out in Mansoura University Hospital, dialysis unit and Hospital Nephrology and Urology, hemodialysis unit, Mitghamr, Egypt.

\subsection{Sample}

Purposive sample of 16 female and 14 male patients was used in this randomized controlled study, Thirty End Stage Renal Disease patients undergoing haemodialysis who admitted to two settings were randomly allocated to experimental group $(\mathrm{n}=18)$ and control group $(\mathrm{n}=12)$ using day randomization technique, aged above 18 to 60 yrs.

\subsubsection{The inclusion criteria}

- Adult patients, male and female (Age $>18$ years).

- Minimum hemodialysis vintage of 3 months.

- Stable on HD, in gender.

- No recent hospitalization.

- No acute or chronic medical conditions that would make exercise training potentially hazardous or primary outcomes impossible to assess.

- Receiving haemodialysis three times/week, for three or four hrs/session.

- Having no problems in arteriovenous (AV) fistulas. ${ }^{[18]}$

- Adequate dialysis therapy: dialysis adequacy index $\mathrm{Kt} / \mathrm{V}>1.2$.

- For all of the patient, a high-flux dialysis membrane was in use.

- Only those patients who used bicarbonate solution were included

- Dietary intake criteria: Unintentional low dietary protein intake $<1 \mathrm{~g} / \mathrm{kg}$ of ideal weight/day for at least 2 months, unintentional low dietary energy intake $<30$ $\mathrm{kcal} / \mathrm{kg}$ of ideal weight/day for at least 2 months.

- Completed a medical screening (see Table 1).

- To investigate eligibility of the patients take Informed consent of the patient.

\subsubsection{The exclusion criteria}

The exclusion criteria are listed in the medical screening form.

Table 1. Medical screening for exclusion criteria to exercise in hemodialysis patients

\begin{tabular}{ll|}
\hline - & Uncontrolled hypertension \\
- & Congestive heart failure \\
- & Unstable angina \\
- & Major valvular heart disease \\
- & Myocardial infarction \\
- & A risnificant arteriosclerosis \\
- & Musculoskeletal disorders \\
- & Change in the resting ECG \\
- & Severe aortic stenosis \\
- & Myspected or known dissecting aneurysm \\
- & Participation in another trial \\
- & Inadequate dialysis Kt/V $<1.2$ \\
- & hemoglobin $<10$ g/dl \\
- & Unstable on dialysis \\
\hline
\end{tabular}

\subsection{Procedure and protocol}

Once the permission granted to proceed with the proposed study, Verbal explanation of the nature and the aim of the studies were performed to medical and nursing staff. The patients who fulfill the inclusion criteria were randomly allotted to 2 groups experimental i.e., (exercise) group $(\mathrm{n}=$ 18) and control group $(n=12)$. All the patients were given information on the purposes of the study, then an informed consent was taken from each patient. The study lasts from June 2014 to November 2014. Range of Motion exercise was prescribed for $15 \mathrm{~min} /$ day, three times a week, during the heamodialysis session. Pre demonstration and post adequate description of the of the exercise technique, the patients demonstrated in 3 training sessions and received the booklet, containing instructions regarding exercise technique. When the patient connected to the dialysis machine and all of the alarms turned off, fatigue was assessed for each group using Iowa Fatigue Scale (IFS) this scale was completed by the patients before the study and post ROM exercise at the end of each 2 months. and staff nurse were drawn blood samples to determine electrolyte level as well as vital signs was assessed. Posttest was conducted immediately after dialysis and at the end of each month. Intradialytic ROM exercise was instructed only to the experimental group beside routine care. ROM exercises lasted for 15 minutes, in the first 2 hours of dialysis according to patients tolerance and stopped next two hours of hemodialysis. ROM exercises performed to all joint of upper and lower limb excluded body part con- 
nected to dialysis machine and paid attention to other limb involved in exercise to avoid disconnection. The prescribed exercises included rotating the wrist as follows: 20 rounds per minute (RPM) clockwise, 20 RPM counter-clockwise, 20 times full flexion and extension of the wrist, 20 times full flexion and extension of the elbow joint, 20 RPM of rotating the ankles clockwise, 20 RPM of rotating the ankles counter-clockwise, 20 times full flexion and extension of the ankles. Additionally vital signs was assessed at least once during exercise. Interestingly inform the patient to report any side effects as nausea, palpitation and headache. Blood samples were compared between experimental and control group at the end of every month post-dialysis (immediately at the end of dialysis session. Blood drowns by the same nurse (see Figure 1).

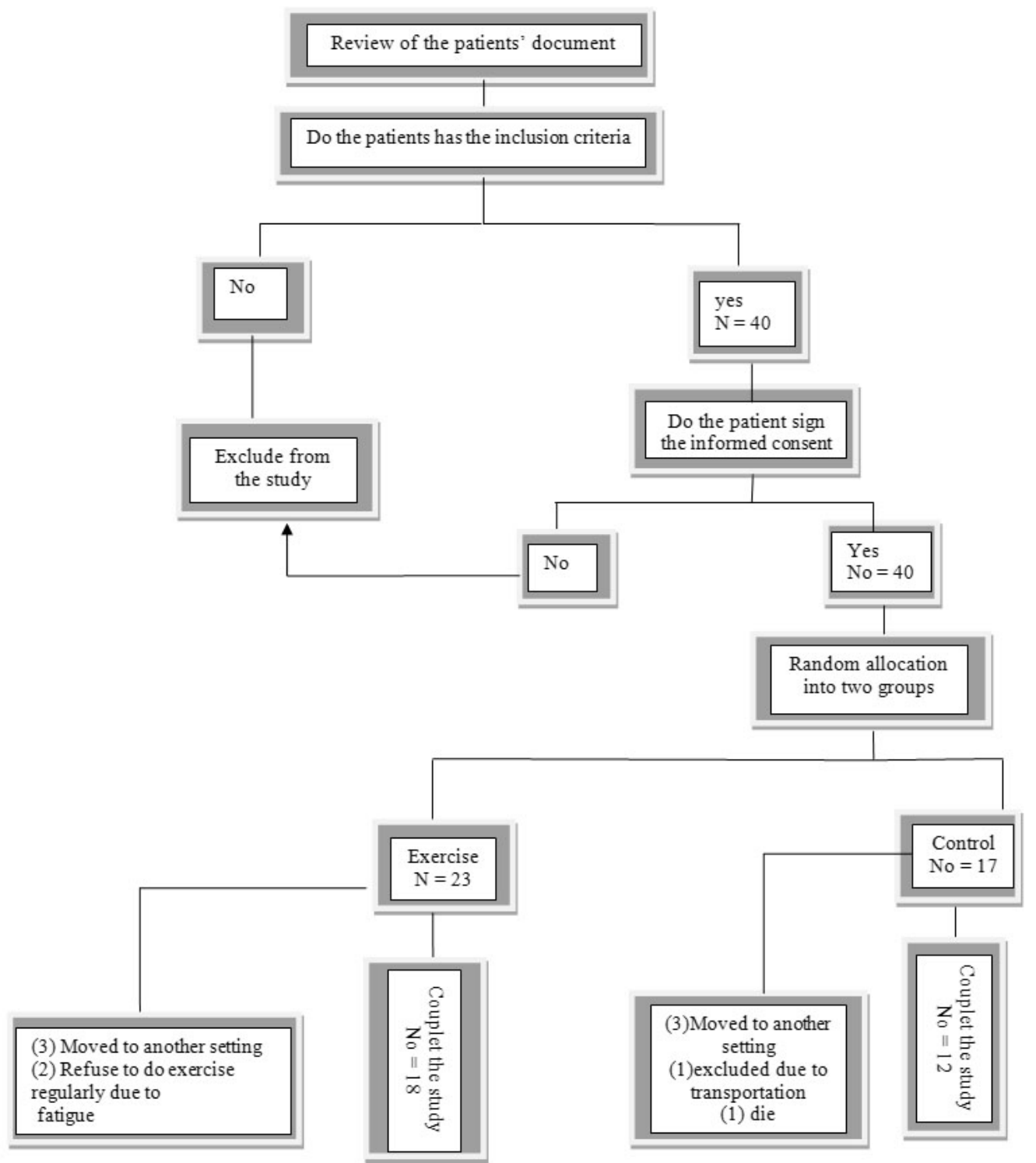

Figure 1. Flowchart of patients throughout the study

\subsection{Data collection}

Data was collected by using 1-Iowa Fatigue Scale (IFS) 2-Sociodemographic questionnaire including age, sex, marital status, period of haemodialysis per month, education, employment condition, and the cause of renal failure and 3-Physiologic Parameters Form which include serum elec- trolytes level, hemoglobin and blood pressure all were used for collecting data. IFS validity and reliability was previously established by. ${ }^{[19]}$ Cronbach's alpha coefficient: 0.93 to 0.95 test-retest reliability $(r=.84)$. IFS included eleven questions that determined level of fatigue. (four questions were in cognitive aspects, a pair of questions were about 
physical fatigue, three questions about energy rate and pair of questions about work output). Fatigue score range was from 11 to 55. Score (11) indicated the minimum fatigue rate and 55 was maximum rate. We divided severity of fatigue in two groups: score from 30 till 39 as fatigue and score from 40 till 55 as severe fatigue. The (IFS) scale was completed by the patients before the study and post ROM exercise at the end of each month. Nephrology nursing staff were drawn Blood samples to measure serum electrolyte level and vital signs were assessed. Posttest was conducted immediately after dialysis and at the end of each month.

\subsection{Conceptual framework}

Conceptual framework of this study was drowned from Myra Estrin Levine's Conservation Model, it focuses on maintaining wholeness and promoting adaptation using the conservation principles. This model direct the researcher on focusing the influences and responses at an organismic level. The investigator validates the outcomes of the model conserving energy, structure, personal and social integrity. This model has 4 variables as (1) conservation of energy, conservation of (2) structural, (3) personal and (4) social integrity. The conserving these variables can result in decreasing fatigue and maintaining activity of daily living. ${ }^{[19,20]}$

\subsection{Ethical consideration}

Written permission was taken from the upper authorities in Mansoura University Hospital, dialysis unit and Hospital Nephrology and Urology, hemodialysis unit, Mitghamr interestingly Ethical research committee of faculty of nursing, Mansoura University, Written informed consent was taken from each participants. ${ }^{[20-22]}$

\subsection{Limitations of study}

Small sample size because of that the researcher performs many tests outside the hospital at the expense of researcher.

\subsection{Need for the study}

Hemodialysis is a physically stressful procedure and most of the patient can have fatigue and thereby a deterioration within the regular activities. Providing exercises throughout the procedure might increase the waste removal and thereby decreasing fatigue. Intradialytic ROM exercise prescribed to enhance dialysis efficacy. The type and frequency of exercise that improve fatigue level, electrolytes and blood pressure in hemodialysis patients not sufficiently examined in research studies. So it's difficult to determine the type of exercise which provide best benefit to Hemodialysis patients. We performed this study to institute Intradialytic exercise that hopefully effective in reducing the level of fatigue and enhancing potential for performing their activities of daily living \& might increase the waste removal as well as improve hemoglobin and blood pressure.

\subsection{Statistical analysis}

Data analysis was done using the SPSS software (Statistical Package for the Social Sciences, version 18.0, SPSS). The plan of data analysis is as follows.

Descriptive statistics: Frequency, percentage distribution, mean, mean percentage and standard deviation.

Inferential statistics: Paired $t$ test, chi square test and independent $t$ test. $P$ value less than .05 used to indicate significance.

\section{RESUltS}

Of the fifty patients on chronic haemodialysis, 40 met the inclusion criteria and agreed to participate within the proposed study, 10 patients were excluded from the study due to death, transplantation or refusing to try to do exercise regularly due to fatigue. Of those, 30 patients completed the study, 18 in experimental group and twelve in control group. As shown in Table 2, no significant changes was discovered in sociodemographic characteristics between the experimental and control group.

It is obvious from Table 2 that there was no significant changes between experimental and control group in age, gender, marital status, living condition education and work status, years on dialysis, Hemodialysis hours, and co-morbidities. And there were a significant change in the two groups regarding years of Hemodialysis where $75 \%$ of control group on Hemodialysis from one to five year and only $38 \%$ of experimental group on Hemodialysis from one to five year. Treatment regimen of Heamodialysis patients not changed for the study period, and no extra drug were prescribed throughout the study period.

When considering the effect of Intradialytic Range of Motion Exercise on fatigue. Table 3 shows that there was a highly statistically significant changes in fatigue score pre and post 8 week between experimental and control group where $p<.001$. In experimental group (exercises group). During pretest $8(44.4 \%)$ of them had mild level of fatigue and $9(50 \%)$ had moderate level of fatigue and $1(5.6 \%)$ had sever fatigue and post 8 week of exercise $18(100 \%)$ had mild fatigue. This showed that the control group patients experiences worst change in fatigue level i.e., the higher the score the worst level of fatigue. During pre test, in control group 9 (75\%)of them had mild level of fatigue \&3 $(25 \%)$ had moderate fatigue. Post 8 week changed to only $6(50 \%$ \& 50\%) mild \& moderate respectively. 
Table 2. Demographic characteristics of hemodialysis patients in experimental (exercise group) and control group (N=30)

\begin{tabular}{|c|c|c|c|c|c|c|}
\hline \multirow{2}{*}{ Characteristics } & \multicolumn{2}{|c|}{ Experimental Group $(\mathrm{n}=18)$} & \multicolumn{2}{|c|}{ Control Group $(n=12)$} & \multirow{2}{*}{$\chi^{2}$} & \multirow{2}{*}{$P$ value } \\
\hline & No & $\%$ & No & $\%$ & & \\
\hline \multicolumn{7}{|l|}{ Age } \\
\hline 20-less than 40 & 4 & $22.2 \%$ & 1 & $8.3 \%$ & 1.700 & .427 \\
\hline 40-less than 60 & 11 & $61.1 \%$ & 7 & $58.3 \%$ & & \\
\hline 60 and more & 3 & $16.7 \%$ & 4 & $33.3 \%$ & & \\
\hline \multicolumn{7}{|l|}{ Gender } \\
\hline Male & 8 & $44.4 \%$ & 6 & $50.0 \%$ & 0.089 & .765 \\
\hline Female & 10 & $55.6 \%$ & 6 & $50.0 \%$ & & \\
\hline \multicolumn{7}{|l|}{ Marital status } \\
\hline Married & 14 & $77.8 \%$ & 11 & $91.7 \%$ & & \\
\hline Single & 3 & $16.7 \%$ & 0 & $0.0 \%$ & 4.333 & .228 \\
\hline Divorced & 0 & $0 \%$ & 1 & $8.3 \%$ & & \\
\hline Widowed & 1 & $5.6 \%$ & 0 & $0.0 \%$ & & \\
\hline \multicolumn{7}{|l|}{ Living Status } \\
\hline Live with family & 17 & $94.4 \%$ & 11 & $91.7 \%$ & 2.173 & .337 \\
\hline Live alone & 0 & $0 \%$ & 1 & $8.3 \%$ & & \\
\hline Live with others & 1 & $5.6 \%$ & 0 & $0.0 \%$ & & \\
\hline \multicolumn{7}{|l|}{ Residence } \\
\hline Rural & 14 & $77.8 \%$ & 11 & $91.7 \%$ & 1.0 & .317 \\
\hline Urban & 4 & $22.2 \%$ & 1 & $8.3 \%$ & & \\
\hline \multicolumn{7}{|l|}{ Income status } \\
\hline Less than 1200 L.E. & 16 & $88.9 \%$ & 10 & $83.3 \%$ & 1.581 & .454 \\
\hline 3000 L.E. & 1 & $5.6 \%$ & 2 & $16.7 \%$ & & \\
\hline More than 3000 L.E. & 1 & $5.6 \%$ & 0 & $0.0 \%$ & & \\
\hline \multicolumn{7}{|l|}{ Education } \\
\hline Illiterate & 6 & $33.3 \%$ & 6 & $50.0 \%$ & & \\
\hline Read and write & 8 & $44.4 \%$ & 4 & $33.3 \%$ & 0.833 & .841 \\
\hline Secondary school & 2 & $11.1 \%$ & 1 & $8.3 \%$ & & \\
\hline University & 2 & $11.1 \%$ & 1 & $8.3 \%$ & & \\
\hline \multicolumn{7}{|l|}{ Work status } \\
\hline Governmental & 2 & $11.1 \%$ & 2 & $16.7 \%$ & & \\
\hline Private & 6 & $33.3 \%$ & 3 & $25.0 \%$ & 0.417 & .937 \\
\hline House wife & 9 & $50 \%$ & 6 & $50.0 \%$ & & \\
\hline Retired & 1 & $5.6 \%$ & 1 & $8.3 \%$ & & \\
\hline \multicolumn{7}{|l|}{ Years on Hemodialysis } \\
\hline Less than one year & 1 & $5.6 \%$ & 2 & $16.7 \%$ & 7.028 & $.030 *$ \\
\hline $1-5$ year & 7 & $38.9 \%$ & 9 & $75.0 \%$ & & \\
\hline \multirow[t]{2}{*}{ Over 5 years } & 10 & $55.6 \%$ & 1 & $8.3 \%$ & & \\
\hline & \multicolumn{2}{|c|}{ Experimental Group $(n=18)$} & \multicolumn{2}{|c|}{ Control Group $(\mathrm{n}=12)$} & $t$ & $P$ value \\
\hline Body mass index & \multicolumn{2}{|c|}{$25.62 \pm 4.29$} & \multicolumn{2}{|c|}{$27.24 \pm 5.74$} & 0.888 & .382 \\
\hline Hemodialysis (hours) & \multicolumn{2}{|c|}{$3.92 \pm 0.19$} & \multicolumn{2}{|c|}{$3.92 \pm 0.29$} & 0.0 & 1.0 \\
\hline No. Hemodialysis per week & \multicolumn{2}{|c|}{$2.94 \pm 0.24$} & \multicolumn{2}{|c|}{$3.08 \pm 0.29$} & 1.446 & .159 \\
\hline
\end{tabular}

Note. Data are presented as No. (\%); ${ }^{*} P<.050$. 
Table 3. Comparison of fatigue level between experimental and control group $(n=30)$ in hemodialysis patients

\begin{tabular}{|c|c|c|c|c|c|c|}
\hline & \multicolumn{2}{|c|}{ Experimental Group $(\mathrm{n}=18)$} & \multicolumn{2}{|c|}{ Control Group (n = 12) } & \multirow{2}{*}{$\chi^{2}$} & \multirow{2}{*}{$P$ value } \\
\hline & No & $\%$ & No & $\%$ & & \\
\hline \multicolumn{7}{|l|}{ Fatigue Pre } \\
\hline Mild & 8 & $44.4 \%$ & 9 & $75.0 \%$ & 2.978 & .226 \\
\hline Moderate & 9 & $50 \%$ & 3 & $25.0 \%$ & & \\
\hline Severe & 1 & $5.6 \%$ & 0 & $0.0 \%$ & & \\
\hline \multicolumn{7}{|c|}{ Fatigue Post } \\
\hline Mild & 17 & $94.4 \%$ & 7 & $58.3 \%$ & 5.868 & $.015^{*}$ \\
\hline Moderate & 1 & $5.6 \%$ & 5 & $41.7 \%$ & & \\
\hline Severe & 0 & $0 \%$ & 0 & $0 \%$ & & \\
\hline \multicolumn{7}{|c|}{ Fatigue 4weeks } \\
\hline Mild & 18 & $100 \%$ & 6 & $50.0 \%$ & 11.250 & $.001^{* *}$ \\
\hline Moderate & 0 & $0 \%$ & 6 & $50.0 \%$ & & \\
\hline Severe & 0 & $0 \%$ & 0 & $0 \%$ & & \\
\hline \multicolumn{7}{|c|}{ Fatigue 8 weeks } \\
\hline Mild & 18 & $100 \%$ & 6 & $50.0 \%$ & 11.250 & $.001 * *$ \\
\hline Moderate & 0 & $0 \%$ & 6 & $50.0 \%$ & & \\
\hline Severe & 0 & $0 \%$ & 0 & $0 \%$ & & \\
\hline
\end{tabular}

$* P<.050 ; * * P<.001$.

When considering the effectiveness of Intradialytic Range of Motion Exercise on fatigue in experimental group (exercises group). The pretest mean score of fatigue in experimental group was 29.89 and post 8 week mean score of fatigue was 14.44 which was statistically significant at $p<.005$. This showed that the patients in experimental group had felt reduced level of fatigue at the end of 8-weeks of practicing Intradialytic range of motion exercise. The level of fatigue within the control (without exercise) group patients. The pretest mean score of fatigue was 26.25 whereas post 8 week mean score of fatigue was declined to 29.75 . This showed that the control group patients experiences worst change in fatigue level i.e., the higher the score the worst level of fatigue. When comparing the fatigue level between the experimental group and the control group patients. There was a statistically significant changes in fatigue score pre and post eight week between experimental and control group where $p$ $<.001$ (see Table 4).

Table 4. Total fatigue score in hemodialysis patients with intradialytic exercise (experimental group) and without intradialytic exercise (control group) ( $\mathrm{N}=30$ )

\begin{tabular}{lllllll}
\hline & & Fatigue pre & Fatigue Post & Fatigue 4weeks & Fatigue 8weeks & $P$ value \\
\hline Experimental Group & Mean \pm SD & $29.89 \pm 6.37$ & $19.44 \pm 5.84$ & $15.56 \pm 4.90$ & $14.44 \pm 5.29$ & $<.001^{* *}$ \\
$(\mathbf{n}=\mathbf{1 8})$ & Range & $22-43$ & $12-34$ & $4-24$ & $6-23$ & $29.75 \pm 5.19$ \\
Control Group & Mean \pm SD & $26.25 \pm 7.40$ & $28.58 \pm 6.71$ & $28.67 \pm 6.62$ & $.006^{*}$ \\
$(\mathbf{n}=\mathbf{1 2})$ & Range & $19-37$ & $12-38$ & $12-38$ & $19-38$ & $<.001^{*}$ \\
$\boldsymbol{P}$ value (between groups) & & 0.162 & $<.001^{*}$ & $<.001^{*}$ & $<$ \\
\hline
\end{tabular}

*Comparison of fatigue level pre versus fatigue at the end of 8 week values in the experimental group; ${ }^{*} P<.050 ; * * P<.001$.

It is clear from Figure 2 that the control group patients experiences worst change in fatigue level i.e., the higher the score the worst level of fatigue and vice versa. There was a statistically significant differences in fatigue score pre and post 8 week between experimental and control group where $p<.001$.

Table 5 reveals that there were no significant relation was observed between fatigue and sociodemographic characteristics in experimental and control group. 


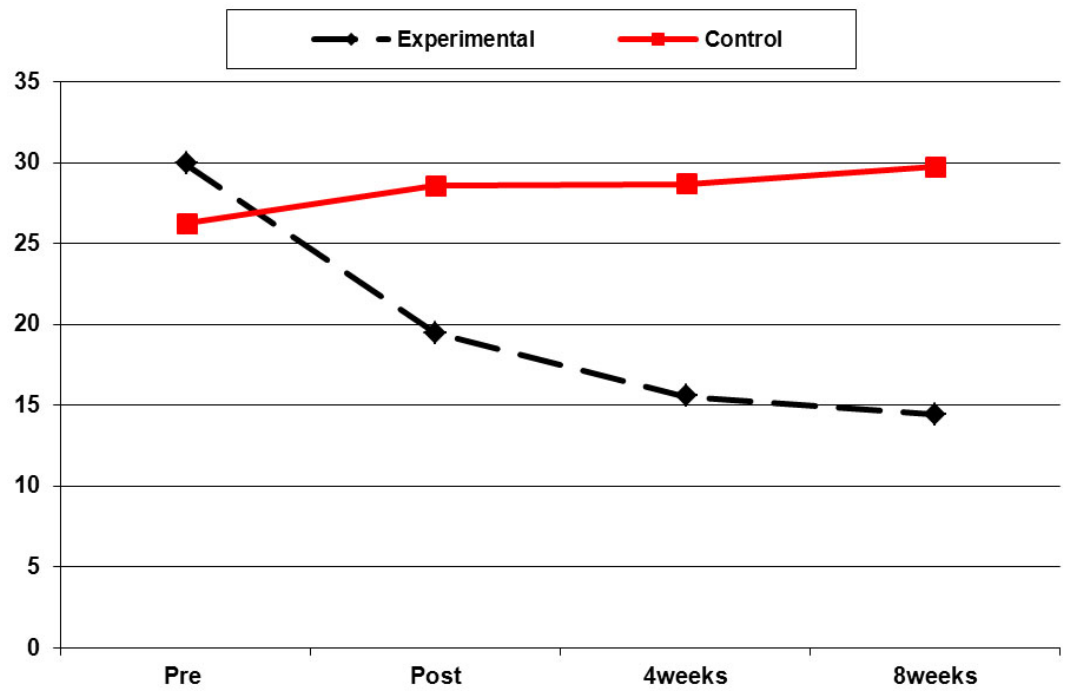

Figure 2. Changes of fatigue scores in control and experimental groups

Table 5. Relation between fatigue and socio demographic variables among experimental and control group $(\mathrm{N}=30)$

\begin{tabular}{|c|c|c|c|c|c|c|}
\hline & $\mathbf{N}$ & Experimental Group $(\mathrm{n}=18)$ & $P$ value & $\mathbf{N}$ & Control Group ( $(n=12)$ & $P$ value \\
\hline \multicolumn{7}{|l|}{ Sex } \\
\hline Male & 8 & $14.75 \pm 4.95$ & \multirow{2}{*}{.834} & 6 & $31.50 \pm 3.73$ & \multirow{2}{*}{.262} \\
\hline Female & 10 & $14.20 \pm 5.81$ & & 6 & $28.00 \pm 6.16$ & \\
\hline \multicolumn{7}{|l|}{ Marital status } \\
\hline Married & 14 & $14.29 \pm 5.36$ & \multirow{3}{*}{.221} & 11 & $30.09 \pm 5.30$ & \multirow{3}{*}{.477} \\
\hline Single & 3 & $12.33 \pm 2.89$ & & 0 & & \\
\hline Widowed & 1 & 23.00 & & 1 & 26.00 & \\
\hline \multicolumn{7}{|l|}{ Living with } \\
\hline Live with family & 17 & $14.76 \pm 5.27$ & \multirow{3}{*}{.304} & 11 & $29.64 \pm 5.43$ & \multirow{3}{*}{.815} \\
\hline Live alone & 0 & & & 1 & 31.00 & \\
\hline Live with others & 1 & 9.00 & & 0 & & \\
\hline \multicolumn{7}{|l|}{ Residence } \\
\hline Rural & 14 & $14.64 \pm 5.14$ & \multirow{2}{*}{.776} & 11 & $30.09 \pm 5.30$ & \multirow{2}{*}{.477} \\
\hline Urban & 4 & $13.75 \pm 6.60$ & & 1 & 26.00 & \\
\hline \multicolumn{7}{|l|}{ Income } \\
\hline Less than 1200 L.E. & 16 & $14.31 \pm 5.38$ & \multirow{2}{*}{.321} & 10 & $29.40 \pm 5.04$ & \multirow{2}{*}{.625} \\
\hline 3000 L.E. & 1 & 20.00 & & 2 & $31.50 \pm 7.78$ & \\
\hline \multicolumn{7}{|l|}{ Education } \\
\hline Illiterate & 6 & $15.67 \pm 6.41$ & \multirow{4}{*}{.691} & 6 & $29.00 \pm 6.26$ & \multirow{4}{*}{.815} \\
\hline Read and write & 8 & $13.13 \pm 3.83$ & & 4 & $30.50 \pm 4.80$ & \\
\hline Secondary school & 2 & $17.50 \pm 4.95$ & & 1 & 27.00 & \\
\hline University & 2 & $13.00 \pm 9.90$ & & 1 & 34.00 & \\
\hline \multicolumn{7}{|l|}{ Work } \\
\hline Governmental & 2 & $8.50 \pm 3.54$ & \multirow{4}{*}{.305} & 2 & $31.00 \pm 4.24$ & \multirow{4}{*}{.765} \\
\hline Private & 6 & $14.50 \pm 5.09$ & & 3 & $31.67 \pm 5.03$ & \\
\hline House wife & 9 & $15.11 \pm 5.35$ & & 6 & $28.00 \pm 6.16$ & \\
\hline Above 70 years & 1 & 20.00 & & 1 & 32.00 & \\
\hline
\end{tabular}


Table 6 reveals that there were a statistically significant changes pre exercises and post 8 week of exercises in all electrolyte level. As shown in Table 7, serum potassium level $\left(\mathrm{K}^{+}\right)$reduced from 5.68 to 4.34 where $(P<.001)$. And calcium level $\left(\mathrm{Ca}^{2+}\right)$ reduced from 8.37 to 7.49 where $(P$ $<.008)$, Phosphate $\left(\mathrm{PO}^{4-}\right)$ level reduced from 7.42 to 7.42 where $(P<.001)$. Serum urea changed from 138.93 to102.44 $(P<.001)$.And serum creatinine changed from 11.02 to 7.95 where $(P<.001)$. When considering the impact of Intradialytic range of motion exercises on systolic and diastolic blood pressure as well as hemoglobin level HGb. There was a statistically significant differences in systolic and diastolic blood pressure pre exercises and post eight week of exercises where $(P<.001)$. Interestingly, there was a statistically significant changes in hemoglobin level pre exercises and post eight week of exercises where $(P<.038)$.

Table 6. Comparison of serum electrolytes and blood pressure between experimental and control group ( $N=30)$

\begin{tabular}{|c|c|c|c|c|c|c|c|c|c|}
\hline \multirow{2}{*}{ Parameters } & \multicolumn{2}{|l|}{ Pre } & \multicolumn{2}{|l|}{ Post } & \multicolumn{2}{|l|}{ 4weeks } & \multicolumn{2}{|l|}{ 8weeks } & \multirow{2}{*}{$P$ value } \\
\hline & Experimental & Control & Experimental & Control & Experimental & Control & Experimental & Control & \\
\hline Potassium mg/dl & $5.68 \pm 0.59$ & $\begin{array}{l}5.81 \pm \\
0.37\end{array}$ & $4.86 \pm 0.67$ & $\begin{array}{l}5.67 \pm \\
0.39\end{array}$ & $4.47 \pm 0.65$ & $\begin{array}{l}5.66 \pm \\
0.35\end{array}$ & $4.34 \pm 0.45$ & $\begin{array}{l}5.61 \pm \\
0.45\end{array}$ & $<.001^{* *}$ \\
\hline Calcium mg/dl & $8.37 \pm 1.03$ & $\begin{array}{l}7.59 \pm \\
0.98\end{array}$ & $7.40 \pm 0.89$ & $\begin{array}{l}7.14 \pm \\
0.90\end{array}$ & $7.31 \pm 0.97$ & $\begin{array}{l}7.49 \pm \\
0.97\end{array}$ & $7.49 \pm 0.77$ & $\begin{array}{l}7.52 \pm \\
0.97\end{array}$ & $.008 * *$ \\
\hline Phosphate mg/dl & $7.42 \pm 1.30$ & $\begin{array}{l}5.55 \pm \\
1.37\end{array}$ & $5.88 \pm 1.51$ & $\begin{array}{l}5.57 \pm \\
1.18\end{array}$ & $5.44 \pm 1.31$ & $\begin{array}{l}5.55 \pm \\
1.14\end{array}$ & $5.33 \pm 1.09$ & $\begin{array}{l}5.50 \pm \\
1.18\end{array}$ & $<.001^{* *}$ \\
\hline Hemoglobin g/dl & $10.28 \pm 2.21$ & $\begin{array}{l}9.40 \pm \\
1.09\end{array}$ & $10.52 \pm 1.88$ & $\begin{array}{l}8.85 \pm \\
0.93\end{array}$ & $10.73 \pm 1.78$ & $\begin{array}{l}9.20 \pm \\
0.78\end{array}$ & $11.04 \pm 1.53$ & $\begin{array}{l}9.19 \pm \\
0.89\end{array}$ & $.038^{* *}$ \\
\hline Serum urea & $138.93 \pm 39.13$ & $\begin{array}{l}141.50 \pm \\
28.67\end{array}$ & $117.56 \pm 35.63$ & $\begin{array}{c}122.75 \pm \\
27.64\end{array}$ & $107.83 \pm 30.69$ & $\begin{array}{l}124.33 \pm \\
28.08\end{array}$ & $102.44 \pm 28.33$ & $\begin{array}{l}124.42 \pm \\
27.31\end{array}$ & $<.001^{* *}$ \\
\hline Serum Creatinin & $11.02 \pm 2.55$ & $\begin{array}{l}11.17 \pm \\
3.24\end{array}$ & $8.79 \pm 2.37$ & $\begin{array}{l}10.48 \pm \\
3.13\end{array}$ & $8.17 \pm 1.91$ & $\begin{array}{l}10.48 \pm \\
3.14\end{array}$ & $7.95 \pm 1.91$ & $\begin{array}{l}10.38 \pm \\
2.97\end{array}$ & $<.001^{* *}$ \\
\hline $\begin{array}{l}\text { Systolic blood } \\
\text { pressure mmHg }\end{array}$ & $132.78 \pm 15.65$ & $\begin{array}{l}136.67 \pm \\
22.29\end{array}$ & $122.78 \pm 14.87$ & $\begin{array}{c}139.17 \pm \\
18.32\end{array}$ & $120.33 \pm 12.64$ & $\begin{array}{l}144.17 \pm \\
15.05\end{array}$ & $117.78 \pm 11.66$ & $\begin{array}{l}143.33 \pm \\
16.14\end{array}$ & $<.001^{* *}$ \\
\hline $\begin{array}{l}\text { Diastolic blood } \\
\text { pressure } \mathrm{mmHg}\end{array}$ & $86.11 \pm 7.78$ & $\begin{array}{l}89.17 \pm \\
9.00\end{array}$ & $80.56 \pm 9.38$ & $\begin{array}{l}89.17 \pm \\
6.69\end{array}$ & $77.50 \pm 7.72$ & $\begin{array}{l}91.67 \pm \\
5.77\end{array}$ & $77.00 \pm 8.24$ & $\begin{array}{l}90.42 \pm \\
8.11\end{array}$ & $<.001^{* *}$ \\
\hline
\end{tabular}

Table 7. Improvement in serum electrolytes and blood pressure in Hemodialysis patients with Intradialytic exercise (Experimental group)

\begin{tabular}{llllll}
\hline Experimental Group & Pre & Post & 4weeks & 8weeks & P value \\
\hline Potassium $\mathrm{K}$ & $5.68 \pm 0.59$ & $4.86 \pm 0.67$ & $4.47 \pm 0.65$ & $4.34 \pm 0.45$ & $<.001^{* *}$ \\
Calcium $\mathrm{Ca}$ & $8.37 \pm 1.03$ & $7.40 \pm 0.89$ & $7.31 \pm 0.97$ & $7.49 \pm 0.77$ & $.008^{*}$ \\
Phosphate $\mathrm{PO}_{4}$ & $7.42 \pm 1.30$ & $5.88 \pm 1.51$ & $5.44 \pm 1.31$ & $7.42 \pm 1.09$ & $<.001^{* *}$ \\
$\mathrm{Hgb}$ & $10.28 \pm 2.21$ & $10.52 \pm 1.88$ & $10.73 \pm 1.78$ & $11.04 \pm 1.53$ & $.038^{* *}$ \\
Serum urea & $138.93 \pm 39.13$ & $117.56 \pm 35.63$ & $107.83 \pm 30.69$ & $102.44 \pm 28.33$ & $<.001^{* *}$ \\
Serum Creatinine & $11.02 \pm 2.55$ & $8.79 \pm 2.37$ & $8.17 \pm 1.91$ & $7.95 \pm 1.91$ & $<.001^{* *}$ \\
Systolic blood pressure mmhg & $132.78 \pm 15.65$ & $122.78 \pm 14.87$ & $120.33 \pm 12.64$ & $117.78 \pm 11.66$ & $<.001^{* *}$ \\
Diastolic blood pressure mmhg & $86.11 \pm 7.78$ & $80.56 \pm 9.38$ & $77.50 \pm 7.72$ & $77.00 \pm 8.24$ & $<.001^{* *}$ \\
\hline
\end{tabular}

${ }^{*} P<.050 ;{ }^{* *} P<.001$.

Table 8. Improvement in serum electrolytes level and blood pressure in Hemodialysis patients without Intradialytic exercise (Control group)

\begin{tabular}{llllll}
\hline Control Group & Pre & Post & 4weeks & 8weeks & P value \\
\hline Potassium K & $5.81 \pm 0.37$ & $5.67 \pm 0.39$ & $5.66 \pm 0.35$ & $5.61 \pm 0.45$ & $<.001^{* *}$ \\
Calcium Ca & $7.59 \pm .98$ & $7.14 \pm 0.90$ & $7.49 \pm 0.97$ & $7.52 \pm 0.97$ & .222 \\
Phosphate $\mathrm{PO}_{4}$ & $5.55 \pm 1.37$ & $5.57 \pm 1.18$ & $5.55 \pm 1.14$ & $5.50 \pm 1.18$ & .804 \\
$\mathrm{Hgb}$ & $9.40 \pm 1.09$ & $8.85 \pm 0.93$ & $9.20 \pm .78$ & $9.19 \pm .89$ & .157 \\
Serum urea & $141.50 \pm 28.67$ & $122.75 \pm 27.64$ & $124.33 \pm 28.08$ & $124.42 \pm 27.31$ & $<.001^{* *}$ \\
Serum Creatinine & $11.17 \pm 3.24$ & $10.48 \pm 3.13$ & $10.48 \pm 3.14$ & $10.38 \pm 2.97$ & $<.001^{* *}$ \\
Systolic blood pressure mmhg & $136.67 \pm 22.29$ & $139.17 \pm 18.32$ & $144.17 \pm 15.05$ & $143.33 \pm 16.14$ & .180 \\
Diastolic blood pressure mmhg & $89.17 \pm 9.00$ & $89.17 \pm 6.69$ & $91.67 \pm 5.77$ & $90.42 \pm 8.11$ & .339 \\
\hline
\end{tabular}

**P<.001. 
Table 8 revealed that there was a statistically significant changes in serum potassium level $\left(\mathrm{K}^{+}\right)$, Serum urea and serum creatinine where $(P<.001)$. But no significant changes in serum calcium level $\left(\mathrm{Ca}^{2+}\right)$ Phosphate $\left(\mathrm{PO}^{4-}\right)$ level. As well as no significant differences in systolic and diastolic blood pressure and hemoglobin level (see Figure 3).

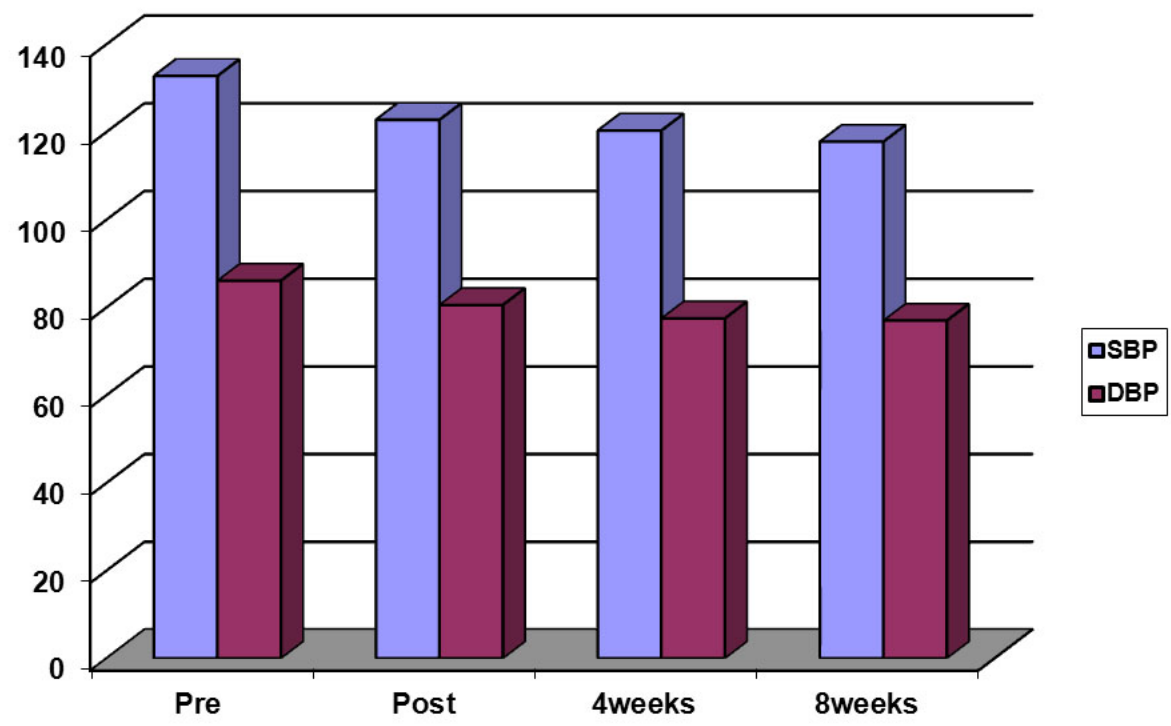

Figure 3. Changes in systolic and diastolic blood pressure in experimental group

(*) $p<.5$

\section{Discussion}

Basically, all patients on long-term Hemodialysis suffer from fatigue. ${ }^{[23]}$ According to Joshwa et al. fatigue occurred in more than $75 \%$ of the patients on hemodialysis. ${ }^{[24]}$ Within the present study, $100 \%$ of the studied sample had experienced fatigue. In our study, there was a significant change in fatigue score pre and post eight week of the exercise program within the experimental group, as well as between experimental and control group where $p<.05$ that was as a result of Intradialytic range of motion exercises for 8 week. Accordingly, Riahi et al. reported that there is a significant reduction in level of fatigue after 5 months of practicing Intradialytic leg exercises. ${ }^{[25]}$ Which was come in accordance with the findings of the present study . Interestingly, Yurtkuran et al. demonstrated that, after 12 week of practicing yoga a significant changes in patients' fatigue level was observed. ${ }^{[26]}$ Similarly in a study done by Chang et al., a significant reduction in level of fatigue post 8 weeks of practicing Intradialytic leg exercises. ${ }^{[27]}$ Whereas the present study didn't need using any special tool and was simply performed within the hospital ward. This is often contradicting to the actual fact that the study had cost the patients extra time other than the dialysis time. By these results we can accept the Hypothesis (1). In this study, we observed that Range of Motion Exercises sessions held during HD was associated with better control of hypertension. There was a high significant improvement in blood pressure readings

Published by Sciedu Press after eight week of exercise in experimental group where $p$ value $<.001$. This come in accordance with a results done by Henrique et al who stated at the end of the exercise program, there was a statistically significant reduction in systolic BP to $143 \pm 14.7 \mathrm{mmHg}$, diastolic BP to $91 \pm 9.6 \mathrm{mmHg}$ and average $\mathrm{BP}$ to $109 \pm 11.4 \mathrm{~mm} \mathrm{Hg}$, despite maintaining the same doses of antihypertensive drugs and the dry weight of patients. ${ }^{[28]}$ So we accept Hypothesis (4).

In the present study We found a significant improvement of most serum electrolytes level with Range of Motion Exercise program during Hemodialysis session. Interestingly, the baseline blood level of phosphate, calcium, urea, creatinine and potassium, as well as hemoglobin were compared between the experimental and control group. The data given here recommend that Range of Motion Exercise program for quarter-hour (15 minutes) throughout haemodialysis sessions improve blood level of potassium and phosphate in a period of 2 month. This findings is also result from effectiveness of aerobics exercise intervention. With a thorough review of accessible research regarding the impact of exercise program on decreasing level of serum phosphate, indicated that in spite of practicing exercise intervention reduce serum phosphate, the valuable changes noticed after long period of time and maybe a lot of intense exercise can be needed for a few patients. ${ }^{[29-31]}$ Furthermore, there is a highly significant change in the Calcium levels post Intradialytic exercise 
program. Intradialytic Exercise program also highly significantly decreased the potassium level at the end of eight week. ${ }^{[32,33]}$ In the control group, the level of potassium, calcium and hemoglobin remained unchanged to end of the study. Additionally, practicing ROM exercise within the 1st hour of hemodialysis improve of phosphate removal from the patients' blood. In a pilot study documented that there is a positive impact of activity on hemoglobin and erythrocytes. ${ }^{[34]}$ Our findings indicated that there is an improvement in level of hemoglobin in experimental group at the end of 8 th week when compared with the start of the study. The improvement in hemoglobin was statistically and clinically important. According to Fallahi and colleagues' study about the effect of 2 months of pedal exercise on hemoglobin they conclude that there was no statistically significant elevation of hemoglobin but a slight elevation of hemoglobin by 0.6 mg dL was observed. ${ }^{[35]}$ The findings of the current study pointed to simply accept the third hypothesis. Our findings revealed the effectiveness of Intradialytic ROM intervention program on hemodialysis patients, on reducing fatigue, serum phosphate, potassium, urea, creatinine and improve of hemoglobin. Also control of blood pressure. So we suggested replication of studies using a large sample size to evaluate impact of Exercise program on different variables as levels of lipid in hemodialysis.

The present study revealed that, there was no significant relation between fatigue level and patients' sex. Interestingly, the findings indicated the incidence and severity of fatigue in women occurs more than men but this findings not confirmed by other studies up to now. ${ }^{[36]}$ Similarly, Chang Jiang concluded the same results and indicated there was no significant difference between fatigue level and patients' sex. ${ }^{[37]}$ Whereas Liu confirmed that women suffering from fatigue more than men do. ${ }^{[38]}$ In our study,age not considered as a predictors of fatigue. Chang et al. stated, the overall fatigue score not changed with age. ${ }^{[37]}$ Supporting role played by the spouses of the patients decreases anxiety, and improve adherence to therapeutic regimen. There was no significant relation between marital status and fatigue severity. ${ }^{[39]}$ Which were in agreement with this result. The present study revealed that, there was no relation between fatigue level in employed and un employed ones. This findings supported by Liu. ${ }^{[38]}$ Controversy, unemployed patients could report a higher fatigue level than employed one because of staying at home can decrease activity level and no support from colleague. But higher education permits patients to institute fatigue relieving measures. ${ }^{[39]}$ In our study illiterate patient and highly educated revealed the same level of fatigue. According the above results we reject the 5th hypothesis.

\section{Conclusions}

Practicing Exercises during haemodialysis session do not cost patients extra time and may be effective in decreasing the fatigue level and enhancing potential for performing their activities of daily living. Demonstrating Intradialytic exercise will improve the effectiveness of dialysis and eliminate long term complications. The type and frequency of exercise that improve fatigue level, electrolytes and blood pressure in hemodialysis patients not sufficiently examined in research studies. So it's difficult to determine the type of exercise which provide best benefit to hemodialysisi patients. In the present study we proposed that 15 minutes of Intradialytic ROM exercise may decrease fatigue level, blood pressure serum phosphate and potassium, and increase in HB. In conclusion, the findings of the present study revealed that the prescribed intra-dialytic ROM exercise resulted in an improvement in fatigue level, also decrease serum phosphate, calcium, potassium levels, urea, creatinine and further as improve $\mathrm{Hb}$ levels and blood pressure reading. However, we need further studies with larger samples to investigate the effect of exercise program on different factors like lipid levels in Hemodialysis patients .

\section{ACKNOWLEDGEMENTS}

The authors would like to acknowledgment the efforts of the Ethical Commette of Faculty of Nursing at Mansoura University, additionally The authors herewith convey thanks to the respected personnel of Mansoura university Hospital, dialysis unit and Hospital Nephrology and Urology, hemodialysis unit, Mitghamr, Egypt and the patients who accept to be involved in the research study. Great thanks to director of two hospitals, the head and staff at the dialysis department as well as to laboratory staff for assistance in implementing the current study. Special thanks to Msaid Magena for editing this research.

\section{CONFlicts OF INTEREST Disclosure}

The author declares that there is no conflict of interest statement.

\section{REFERENCES}

[1] Mula-Abed WA, Al Rasadi K, Al-Riyami D. Estimated Glomerular Filtration Rate (eGFR): A Serum Creatinine-Based Test for the Detection of Chronic Kidney Disease and its Impact on Clinical Practice. Oman Med J. 2012 Mar; 27(2): 108-113. PMid:22496934 http://dx.doi.org/10.5001/omj.2012.23

[2] Zhang QL, Rothenbacher D. Prevalence of chronic kidney disease in population-based studies: systematic review. BMC Public Health. 2008; 8: 117. PMid:18405348 http://dx.doi.org/10.1186/1 471-2458-8-117 
[3] Burrows NR, Li Y, Geiss LS. Incidence of treatment for end-stage renal disease among individuals with diabetes in the U.S. continues to decline. Diabetes Care. 2010 Jan; 33(1): 73-77. PMid:20040673 http://dx.doi.org/10.2337/dc09-0343

[4] Foley RN, Collins AJ. End-stage renal disease in the United States: an update from the United States Renal Data System. J Am Soc Nephrol. 2007 Oct; 18(10): 2644-2648. PMid:17656472 http: //dx.doi.org/10.1681/ASN. 2007020220

[5] National Institute of Diabetes and Digestive and Kidney Diseases (NIDDKD) Chronic kidney disease-mineral bone disorder. 2009.

[6] Cheema BS, Singh MA. Exercise training in patients receiving maintenance hemodialysis: a systematic review of clinical trials. Am J Nephrol. 2005 Jul-Aug; 25(4): 352-364. PMid:16088076 http://dx.doi.org/10.1159/000087184

[7] Checheriţă IA, Turcu F, Dragomirescu RF, et al. Chronic complications in hemodialysis: correlations with primary renal disease. Rom J Morphol Embryol. 2010; 51(1): 21-26. PMid:20191115

[8] Cronin RE, Henrich WL. Kt/V and the adequacy of hemodialysis. 2013. Available from: http://www.uptodate.com/contents/ $\mathrm{kt}$-v-and-the-adequacy-of-hemodialysis

[9] Borzo R, Galyaf M, Amin R. Assessment of velocity of blood flow affect on adequacy of dialysis in haemodialysis patients. Shahrekord Univ Med Sci J. 2006; 8(2): 60-61.

[10] Jablonski A. The multidimensional characteristics of symptoms reported by patients on hemodialysis. Nephrology Nursing Journal. 2007; 34(1): 29-37. PMid: 17345690

[11] Weisbord S, Fried L, Arnold R, et al. Prevalence, severity, and importance of physical and emotional symptoms in chronic hemodialysis patients. Journal of the American Society of Nephrology. 2005; 16(8): 2487-2494. PMid:15975996 http://dx.doi.org/10.1681/ASN .2005020157

[12] Murtaugh F, Addington-Hall J, Higginson I. The prevalence of symptoms in end stage renal disease: A systematic review. Advances in Chronic Kidney Disease. 2007; 14(1): 82-99. PMid:17200048 http://dx.doi.org/10.1053/j.ackd.2006.10.001

[13] Jhamb M, Weisbord S, Steel J, et al. Fatigue in patients receiving maintenance dialysis: A review of definitions, measures, and contributing factors. American Journal of Kidney Disease. 2008; 52(2): 353-365. PMid:18572290 http://dx.doi.org/10.1053/j.ajk d. 2008.05.005

[14] Mahrova A, Svagrova K. Exercise Therapy-Additional Tool for Managing Physical and Psychological Problems on Hemodialysis. In: Suzuki H editor. Hemodialysis. InTech; 2013. PMid:23511720 http://dx.doi.org/10.5772/53058

[15] Gordon PL, Doyle JW, Johansen KL. Postdialysis fatigue is associated with sedentary behavior. Clinical Nephrology. 2011; 75(5): 426-433. PMid:21543022

[16] Kosmadakis GC, Bevington A, Smith AC, et al. Physical exercise in patients with severe kidney disease. Nephron Clinical Practice. 2010; 115(1): c7-c16. PMid:20173344 http://dx.doi.org/10. $1159 / 000286344$

[17] Koh KP, Fassett RG, Sharman JE, et al. Intradialytic versus homebased exercise training in hemodialysis patients: a randomized controlled trial. BMC Nephrol. 2009; 10: 1-6. PMid:19178747 http://dx.doi.org/10.1186/1471-2369-10-2

[18] Parsons TL, Toffelmire EB, King-VanVlack CE. The effect of an exercise program during hemodialysis on dialysis efficacy, blood pressure and quality of life in end-stage renal disease (ESRD) patients. Clin Nephrol. 2004 Apr; 61(4): 261-274. PMid:15125032 http://dx.doi.org/10.5414/CNP61261

Published by Sciedu Press
[19] Hartz A, Bentler S, Watson D. Measuring fatigue severity in primary care patients. Journal of psychosomatic research. 2003; 54(6): 51521. http://dx.doi.org/10.1016/S0022-3999(02)00600-1

[20] Delgado C, Johansen KL. Barriers to exercise participation among dialysis patients. Nephrology Dialysis Transplantation. 2012; 27(3): 1152-1157. PMid:21795245 http://dx.doi.org/10.1093/ndt /gfr404

[21] Dobsak P, Homolka P, Svojanovsky J, et al. Intra-dialytic electrostimulation of leg extensors may improve exercise tolerance and quality of life in hemodialyzed patients. Artificial Organs. 2012; 36(1): 718. PMid:21848929 http://dx.doi.org/10.1111/j.1525-159 4.2011.01302. $\mathrm{x}$

[22] Dong J, Sundell MB, Pupim LB, et al. The effect of resistance exercise to augment long-term benefits of intradialytic oral nutritional supplementation in chronic hemodialysis patients. Journal of Renal Nutrition: the Official Journal of the Council on Renal Nutrition of the National Kidney Foundation. 2010; 21(2): 149-59. PMid:20580251 http://dx.doi.org/10.1053/j.jrn.2010.03.004

[23] Horigan A, Rocchiccioli J, Trimm D. Dialysis and fatigue: implications for nurses-a case study analysis. Medsurg Nurs. 2012; 21(3): 158-63. PMid:22866436

[24] Joshwa B, Khakha DC, Mahajan S. Fatigue and depression and sleep problems among hemodialysis patients in a tertiary care center Saudi J Kidney Dis Transpl. 2012; 23(4): 729-35. PMid:22805385 http://dx.doi.org/10.4103/1319-2442.98149

[25] Riahi Z, Esfarjani F, Marandi SM, et al. The effect of intradialytic exercise training on the quality of life and fatigue in hemodialysis patients. J Res Rehabil Sci. 2012; 8(2): 219-27.

[26] Yurtkuran M, Alp A, Yurtkuran M, et al. A modified yoga-based exercise program in hemodialysis patients: a randomized controlled study. Complement Ther Med. 2007; 15(3): 164-71. PMid:17709061 http://dx.doi.org/10.1016/j.ctim.2006.06.008

[27] Chang Y, Cheng SY, Lin M, et al. The effectiveness of intradialytic leg ergometry exercise for improving sedentary life style and fatigue among patients with chronic kidney disease: a randomized clinical trial. Int J Nurs Stud. 2010; 47(11): 1383-8. PMid:20537645 http://dx.doi.org/10.1016/j.ijnurstu.2010.05.002

[28] Henrique D, Reboredo M, Baumgratz A. Aerobic Exercise Improves Physical apacity in Patients under Chronic Hemodialysis Sociedade Brasileira de Cardiologia. Sociedade Brasileira de Nefrologia. IV Diretriz para uso da monitorização ambulatorial da pressão arterial. Arq Bras Cardiol. 2011; 85 (supl. 2): 1-18.

[29] Asadi Noghabi A, Bassampour SH, Zolfaghari M. Critical care nursing ICU, CCU, dialysis. Salemi publication; 2th ed. 2007; 448-53.

[30] Cappy CS, Jablonka J, Schroeder ET. The effects of exercise during hemodialysis on physical performance and nutrition assessment. J Ren Nutr. 1999; 9: 63-70. http://dx.doi.org/10.1016/S1051 -2276 (99) 90002-X

[31] Vaithilingam I, Polkinghorne KR, Atkins RC, et al. Time and exercise improve phosphate removal in Hemodialysis patients. Am J Kidney Dis. 2004; 43: 85-9. http://dx.doi.org/10.1053/j.ajkd. 20 03.09 .016

[32] Borzou R, Galyaf M, Amin R. Assessment of effect of increased blood flow on blood levels of potassium and phosphorus in hemodialysis patients. Ardebil Univ Med Sci. 2008; 8: 235-40.

[33] Man NK, Chauveau P, Kuno T, et al. Phosphate removal during hemodialysis, hemodiafiltration, and hemofiltration. A reappraisal. ASAIO Trans. 1991; 37: M463-5. PMid:1751238

[34] Coyne DW, Delmez J, Spence G, et al. Impaired delivery of hemodialysis prescriptions: an analysis of causes and an approach to evaluation. J Am Soc Nephrol. 1997; 8: 1315-8. PMid:9259360 
[35] Fallahi M, Shahidi SH, Farajzadegan Z. The effect of intradialytic exercise on dialysis efficacy, serum phosphate, hemoglobin and blood pressure control and comparison between two exercise programs in hemodialysis patients. Isfahan Med Sci J. 2007; 26: 152-61.

[36] Fatigue in chronic dialysis patients. In: Bossola M, Vulpio C, Tazza L editors. Seminars in dialysis. Wiley Online Library; 2011. 550-5.

[37] Chang Y, Cheng SY, Lin M, et al. The effectiveness of intradialytic leg ergometry exercise for improving sedentary life style and fatigue among patients with chronic kidney disease: a randomized clini- cal trial. Int J Nurs Stud. 2010; 47(11): 1383-8. PMid:20537645 http://dx.doi.org/10.1016/j.ijnurstu.2010.05.002

[38] Liu HE. Fatigue and associated factors in hemodialysis patients in Taiwan. Res Nurs Health. 2006; 29(1): 40-50. PMid:16404733 http://dx.doi.org/10.1002/nur.20109

[39] Mollaoglu M. Fatigue in people undergoing hemodialysis. Dialysis Transplant. 2009; 38(6): 216-20. http://dx.doi.org/10.1002 /dat. 20330 